\title{
Predictors of Hyporesponsiveness to Erythropoiesis-Stimulating Agents in Hemodialysis Patients
}

\author{
Kamyar Kalantar-Zadeh, MD, MPH, PhD $^{1,2}$, Grace H Lee, PharmD ${ }^{3}$, Jessica E. Miller, \\ MPH $^{1,2}$, Elani Streja, MPH ${ }^{1,2}$, Jennie Jing, $\mathbf{M S}^{1}$, John A Robertson, MD ${ }^{4}$, and Csaba P. \\ Kovesdy, MD 5 \\ 1 Harold Simmons Center for Kidney Disease Research and Epidemiology, Los Angeles Biomedical Research \\ Institute at Harbor-UCLA Medical Center, Torrance, CA \\ 2 Department of Epidemiology, UCLA School of Public Health, Los Angeles, CA \\ 3 Department of Pharmacy, Harbor-UCLA Medical Center, Torrance, CA \\ 4 DaVita, Inc, El Segundo, CA 90245 \\ 5 Salem Veteran Administration Medical center, Salem, VA
}

\begin{abstract}
Background-Identification of predictors of hyporesponsiveness to erythropoietin-stimulating agents (ESA) in hemodialysis (HD) patients may help improve anemia management and reduce hemoglobin variability.

Study Design-We conducted repeated measure and logistic regression analyses in a retrospective cohort of long-term HD patients to examine the association of iron markers and measures of renal osteodystrophy with ESA-responsiveness. The ESA-response coefficient at the individual level, i.e., the least-confounded dose-response association, was separated from the population level, assumed to represent confounding by medical indication.
\end{abstract}

Setting/Participants-The national database of a large dialysis organization (DaVita) with 38,328 surviving prevalent HD patients over 12 months, who received ESA for at least 3 consecutive calendar quarters, was examined.

Predictors-Serum levels of ferritin, iron saturation ratio (ISAT), intact parathyroid hormone (PTH) and alkaline phosphatase levels.

Outcomes/Other Measurements-The main outcome was case-mix adjusted hemoglobin response to quarterly averaged ESA dose at individual level. The odds ratio (OR) of the greatest vs. poorest ESA-response quartile at patient level was calculated. OR $<1.0$ indicated ESA hyporesponsiveness and $\mathrm{OR}>1.0$ enhanced responsiveness.

Results-The mean $( \pm \mathrm{SD})$ ESA-response coefficients of the least to most responsive quartiles were $0.301 \pm 0.033,0.344 \pm 0.004,0.357 \pm 0.004$, and $0.389 \pm 0.026 \mathrm{~g} / \mathrm{dL}$ higher hemoglobin per 1,000 units/ week higher ESA dose in each quarter, respectively. The ORs of the greatest vs. poorest ESA-

Correspondence: Kamyar Kalantar-Zadeh, MD, MPH, PhD, Harold Simmons Center for Kidney Disease Research and Epidemiology, Los Angeles Biomedical Research Institute at Harbor-UCLA Medical Center, 1124 West Carson Street, C1-Annex, Torrance, CA 90509-2910, Phone: 310-222-3891, Fax: 310-782-1837, E-mail: E-mail: kamkal@ucla.edu.

Publisher's Disclaimer: This is a PDF file of an unedited manuscript that has been accepted for publication. As a service to our customers we are providing this early version of the manuscript. The manuscript will undergo copyediting, typesetting, and review of the resulting proof before it is published in its final citable form. Please note that during the production process errors may be discovered which could affect the content, and all legal disclaimers that apply to the journal pertain. 
responsiveness at patient level were the following: Serum ferritin $<200 \mathrm{ng} / \mathrm{ml}: 0.77$ [95\% confidence interval: 0.70-0.86] (reference: $200-500 \mathrm{ng} / \mathrm{ml}$ ), ISAT<20\%: 0.54 [0.49-0.59] (reference: $20-30 \%$ ), intact PTH $\geq 600 \mathrm{pg} / \mathrm{ml}: 0.54$ [0.49-0.60] (reference: $150-300 \mathrm{pg} / \mathrm{ml}$ ), and alkaline phosphatase $\geq 160$ IU/L: 0.64 [0.58-0.70] (reference: 80-120 IU/L). Lower estimated dietary protein intake and serum levels of nutritional markers were also associated with higher risk of ESA-hyporesponsiveness.

Limitations-Our results may incorporate uncontrolled confounding. Achieved hemoglobin may have different associations than targeted hemoglobin.

Conclusions-In long-term HD patients, low iron stores, hyperparathyroidism and high turnover bone disease are associated with significant ESA-hyporesponsiveness. Prospective studies are needed to verify these associations.

\section{Keywords}

Erythropoiesis stimulating agent (ESA); chronic kidney disease (CKD); hemoglobin variability; iron markers; ESA hyporesponsiveness; high turnover bone disease; confounding by medical indication (CMI); repeated measure model

\section{Introduction}

The anemia of chronic kidney disease (CKD) is a multi-factorial disorder that can be managed successfully by erythropoiesis-stimulating agents (ESA) administration.[1,2] However, the required dose of ESA is quite variable in different CKD patients or in the same patient at different periods of time.[3,4] A recent study found that very high ESA doses are virtually ineffective in increasing hemoglobin.[5] Indeed exceptionally high ESA doses may be associated with increased platelet count [6] and poor clinical outcomes.[7] Hence, identification of factors that enhance ESA responsiveness can optimize anemia management and reduce hemoglobin variability,[8] Both ESA-hyporesponsiveness and hemoglobin variability may be associated with increased death risk.[9-11] The malnutrition-inflammation complex, iron deficiency, and hyperparathyroidism may be associated with the ESA hyporesponsiveness.[12-15] However, the predictors of ESA-hyporespponsiveness have not been well studied.

Adequate iron stores and correction of hyperparathyroidism may significantly enhance the responsiveness to ESA in CKD patients including in long-term hemodialysis (HD) patients, who comprise over $90 \%$ of all long-term dialysis patient population in the United States.[16, 17] The National Kidney Foundation Kidney Disease Outcome Dialysis Initiative (KDOQI) guidelines suggest that a serum iron saturation ratio (ISAT) above $20 \%$ and a serum ferritin above $200 \mathrm{ng} / \mathrm{ml}$ would provide optimal iron stores for anemia management in patients.[18, 19] The KDOQI guidelines on bone and mineral disorders (BMD) suggest that serum parathyroid levels be between 150 and $300 \mathrm{pg} / \mathrm{ml}$.[20] Several recent studies found that a high serum alkaline phosphatase level, a surrogate of high turnover bone disease, is associated with increased death risk.[21-23] We hypothesized that low serum ferritin and ISAT levels and high serum intact PTH and alkaline phosphatase concentrations are associated with ESA hyporesponsiveness in long-term HD patients.

\section{Methods}

Patients

We extracted, refined, and examined data from all individuals with CKD stage 5, who underwent HD treatment for 12 months from July 1, 2001, to June 30, 2002, in one of the 580 outpatient dialysis facilities of a large dialysis organization in the United States, i.e., DaVita, Inc, (prior to its acquisition of former Gambro dialysis facilities). The information about anemia 
management in this cohort has already been presented in our previous publications.[24,25] In the current study, the cohort is restricted to the first 12 months of the previously studied 2-year [24-27] or 3-year cohorts [28-31] to mitigate the likelihood that changes in practice pattern including alteration in reimbursement and internal or external guidelines affected the anemia management during the study period. The selected participants had to meet the following inclusion criteria: (1) they remained in the cohort for the entire 12 month; (2) had been on dialysis for at least 3 months on July 1, 2001; (3) did not switch to peritoneal dialysis or other modalities; and (4) received ESA for at least once monthly for 9 consecutive months over three consecutive calendar quarters. We studied surviving patients exclusively, so that the effect of worsening clinical conditions prior to death on ESA responsiveness could be mitigated. The study was approved by the Institutional Review Committees of both Los Angeles Biomedical Research Institute at Harbor-UCLA and DaVita Clinical Research; and because of the large sample size studied, the anonymity of the patients studied, and the nonintrusive nature of the research, the requirement for a written consent form was exempted.

\section{Clinical and Demographic Measures}

To minimize measurement variability, all repeated measures for each patient during any given calendar quarter, i.e., over a 13-week interval, were averaged and the summary estimate was used in all models. Averaged values were obtained for up to four calendar quarters for each laboratory and clinical measure for each patient over the 12-month cohort period. Dialysis vintage was defined as the duration of time between the first day of dialysis treatment and the first day that the patient entered the cohort. The first (baseline) studied quarter for each patient was the calendar quarter, in which patient's vintage was $>90$ days during at least half of the time of that given quarter. The doses of injected ESA, i.e., recombinant human erythropoietin (rHuEPO, epogen ${ }^{\mathrm{TM}}$, Amgen, Inc, Thousand Oaks, CA), were also calculated for each calendar quarter.

In addition to the presence or absence of diabetes mellitus, which was available in the database, histories of tobacco smoking and preexisting comorbid conditions were obtained by linking the DaVita database to the Medical Evidence Form 2728 of the United States Renal Data System (USRDS) [32] and categorized into 11 comorbid conditions: (1) ischemic heart disease, (2) congestive heart failure, (3) status post (s/p) cardiac arrest, (4) s/p myocardial infarction, (5) pericarditis, (6) cardiac dysrhythmia, (7) peripheral vascular disease (8) chronic obstructive pulmonary disease, (9) HIV/AIDS status, (10) ambulatory status, and (11) cancer.

\section{Laboratory Measures}

Blood samples were drawn using uniform techniques in all of the DaVita dialysis clinics and were transported to the DaVita Laboratory in Deland, Florida, typically within $24 \mathrm{hrs}$. All laboratory values were measured by automated and standardized methods in the DaVita Laboratory. Most laboratory values, including complete blood cell counts and serum levels of iron, total iron binding capacity (TIBC), urea nitrogen, creatinine, albumin, calcium, phosphorus, and bicarbonate were measured monthly. Serum ferritin and intact parathyroid hormone (PTH) were measured at least quarterly. Hemoglobin was measured at least monthly in essentially all patients and weekly to biweekly in most patients. Kt/V was used to estimate dialysis dose and normalized protein equivalent of total nitrogen appearance (nPNA), also known as normalized protein catabolic rate (nPCR), an estimation of daily protein intake, were measured monthly as a measure of protein intake. Blood samples were collected pre-dialysis with the exception of the post-dialysis serum urea nitrogen that was obtained to calculate urea kinetics. 


\section{Epidemiologic and Statistical Methods}

To study the relation between blood hemoglobin and the prescribed ESA dose in long-term HD patients, our biologically plausible assumption is that higher administered ESA dose leads to higher hemoglobin levels as originally described by Eschbach et al.[33] At the population level, however, HD patients with ESA-hyporesponsive anemia paradoxically receive higher ESA doses to achieve the same hemoglobin target as those who are better responsive; this phenomenon, also known as "confounding by medical indication" (CMI), has been previously described for the administered doses of ESA and active vitamin D in CKD populations.[5, 34] Therefore when evaluating the relation between ESA and hemoglobin levels crosssectionally within the population, a higher ESA dose is associated with a lower hemoglobin levels as a result of the CMI (Figure 1). Nevertheless, within each individual, a higher ESA dose should still result in higher hemoglobin levels over time. Therefore examination of longitudinal models at individual level with repeated measures over time should more genuinely disclose the underlying and biologically plausible dose-response associations (see also the Technical Appendix for more details about the statistical methods).

To examine individual associations between ESA and hemoglobin over time, we used a linear mixed model (SAS PROC MIXED, specifying a random intercept and ESA as a random effect. [35] Hemoglobin response is modeled over the 4 consecutive calendar quarters (seasons) between July 2001 and June 2002. We then ranked patients according to the magnitude of their individual longitudinal slope $\left(\boldsymbol{\beta}_{\mathbf{L}}\right)$ where a higher individual $\boldsymbol{\beta}_{\mathbf{L}}$ corresponds to greater hemoglobin response to ESA over time. To examine predictors of ESA responsiveness, we created an "ESA responsiveness" variable, comparing those who ranked in the highest quartile $\left(\geq 75^{\text {th }}\right.$ percentile) of individual slopes to those who ranked in the lowest quartile $\left(\leq 25^{\text {th }}\right.$ percentile). We then employed logistic regression modeling, evaluating predictors of ESA responsiveness. For each analysis both the unadjusted and case-mix multivariate adjusted models were examined. Case-mix adjusted models were controlled for age, sex, race and ethnicity (African Americans and other self-categorized African Americans, Non-Hispanic Whites, Asians, Hispanics and others), diabetes mellitus and 11 pre-existing comorbid states, history of tobacco smoking, categories of dialysis vintage ( 3 to 6 mo, 6 mo to 2 yrs, $2-5$ yrs and $\geq 5 \mathrm{yrs}$ ), primary insurance (Medicare, Medicaid, private and others), marital status (married, single, divorced, widowed and other or unknown), the standardized mortality ratio of the dialysis clinic during entry quarter, dialysis dose as indicated by Kt/V (single pool), presence or absence of a dialysis catheter, and residual renal function during the entry quarter, i.e. urinary urea clearance. Each laboratory variable or IV iron was examined independently of others as a predictor in separate multivariate models that were adjusted for the abovementioned case-mixed covariates. All descriptive and multivariate statistics were carried out with the SAS, version 8.02, SAS Institute, Inc., Cary, North Carolina. Due to the large sample size, most p-values tend to be small.

\section{Results}

The original 12-month (7/2001-6/2002) national database of DaVita included 49,215 longterm HD patients who originated from the first two calendar quarters of this period and who remained in the cohort for 3 consecutive quarters. After exclusion of patients who have been on dialysis for less than 3 months or who did not meet the inclusion criteria, 38,393 patients remained in the cohort. Of these, 65 patients were excluded in whom the core case-mix data or data related to anemia management were missing, leading to 38,328 long-term HD patients for this study.

Table 1 shows the characteristic of HD patients in the four quartiles of the ESA responsiveness coefficients $\beta_{\mathrm{L}}$. After normalizing the ESA-response coefficients into positive values, the mean $( \pm \mathrm{SD})$ coefficients of the least to most responsive quartiles were $0.301 \pm 0.033,0.344 \pm 0.004$, 
$0.357 \pm 0.004$, and $0.389 \pm 0.026$, respectively. Women comprised $46 \%$ to $48 \%$ of each quartile. Patients in the first quartile (the "ESA-hyporesponsive" group) were on average 2 years younger than other groups and included more African Americans ${ }_{[\mathrm{EF} 1]}$ and less Hispanic patients. The ESA-hyporesponsive group also had the lowest serum albumin, TIBC, iron, ISAT and ferritin and highest intact PTH and alkaline phosphatase levels. To verify the accuracy of our quartile classification, we calculated the cross-sectional ESA responsiveness coefficient $\left(\beta_{\mathrm{c}}\right)$ separately in each of the responsiveness quartiles and found that the absolute value of $\beta_{\mathrm{c}}$ in the first (ESA-hyporesponsive) quartile was 3 times higher than the entire cohort $\beta_{c}$, whereas the magnitude of the $\beta_{\mathrm{c}}$ in the $4^{\text {th }}$ (most ESA responsive) quartile was $30 \%$ lower than the entire cohort $\beta_{\mathrm{c}}$.

We conducted logistic regression analyses to calculate the odds ratio (OR) of the "most ESA responsive" (highest quartile) to the "least responsive" (ESA-hyporesponsive quartile). An OR $>1.0$ implies greater ESA responsiveness with the given variable, whereas OR $<1.0$ indicates more severe ESA hyporesponsiveness or refractory anemia. Table 2 shows the both the unadjusted and case-mix multivariate adjusted OR of ESA responsiveness for relevant variables. Women and African Americans and those with a dialysis catheter were significantly more ESA hyporesponsive, whereas Hispanics had better ESA responsiveness compared to non-Hispanic whites. Most comorbid states including HIV, cancer and heart failure were associated with worse ESA response, as was the inability to ambulate. Lower nPNA (nPCR), a urea-kinetic estimate of dietary protein intake,[27] was associated with higher risk of ESAhyporesponsiveness. Among laboratory variables, higher serum levels of albumin, creatinine, ferritin, ISAT, and calcium were associated with greater ESA responsiveness, whereas increasing serum phosphorus and intact PTH levels had the opposite association. The likelihood of requiring IV iron administration in case mix adjusted model was $14 \%$ lower in the most ESA responsive quartile.

We studied the association of different ranges of the iron markers and ESA responsiveness. As shown in Figure 2, after dividing the entire serum ISAT range into 4 a priori selected groups $(<20,20-30$ [reference], 30-50, and $>=50 \%)$, the greatest ESA responsiveness was observed with ISAT $>30 \%$, whereas ISAT $<20 \%$ was associated with almost 50\% lower ESAresponsiveness including after adjustment for case-mix variables (unadjusted and adjusted OR: 0.53 and $0.54,95 \%$ CI: $0.48-0.58$ and $0.49-0.59$, respectively, $\mathrm{p}<0.001)$. [EF2] Similarly, after dividing serum ferritin range into 5 a priori selected groups $(<200,200-500$ [reference], 500$800,800-1,200$, and $>=1,200 \mathrm{ng} / \mathrm{ml}$ ), the greatest ESA-responsiveness was observed with serum ferritin in 500 to $1,200 \mathrm{ng} / \mathrm{ml}$ range, whereas ferritin $<200 \mathrm{ng} / \mathrm{mL}$ was associated with 23\% lower responsiveness (adjusted OR: 0.77, 95\% CI: 0.70-0.86, $\mathrm{p}<0.001$ ). Figure 3 shows the results of similar analyses for serum intact PTH and alkaline phosphatase concentrations. The case-mix adjusted OR of the greatest vs. poorest ESA responsiveness at patient level for intact PTH $\geq 600 \mathrm{pg} / \mathrm{ml}$ (reference: $150-300 \mathrm{p} / \mathrm{ml}$ ) was 0.54 (95\% CI: $0.49-0.60$ ) and for serum alkaline phosphatase $\geq 160$ IU/L (reference: $80-120$ IU/L) was 0.64 (95\% CI: 0.58-0.70).

\section{Discussion}

In a 12-month contemporary cohort of 38,328 surviving prevalent HD patients who had received ESA continuously, we used repeated measure models to examine conditions related to ESA-responsiveness at individual level independent of the population level associations. We found that more women and African Americans were among the "ESA-hyporesponsive" quartile. The logistic regression calculated OR of the most to least ESA responsiveness identified conditions that were independently associated with ESA-hyporesponsiveness including dialysis catheter, most comorbid states, indicators of protein-energy malnutrition such as hypoalbuminemia and low dietary protein intake, indicators of renal osteodystrophy such as hyperparathyroidism and high serum alkaline phosphatase, and surrogates of low iron 
stores including low serum ferritin and ISAT. These findings may have important clinical implications in the management of anemia in CKD patients especially those undergoing $\mathrm{HD}$ treatment.

The management of anemia in CKD patients is usually based on administering ESA and other medications such as iron products.[36] In the USA approximately two billion dollars of the annual Medicare budget is spent for anemia management in dialysis patients, mostly towards reimbursement of ESA in dialysis clinics.[37] The amount of the administered ESA to dialysis patients has increased in the past 15 years.[38,39] Recent data indicating the administration of exceptionally high ESA doses in some dialysis organizations [38] have lead to concerns regarding both the finances and safety of such a practice.[5,36,40] Indeed "targeting" higher hemoglobin levels, e.g. above $13 \mathrm{~g} / \mathrm{dl}$, were associated with increased death risk in randomized controlled trials,[7,41-43] esp. among those who are ESA-hyporesponsive.[11,44] A recent study indicted that high ESA doses, esp. if concurrent with iron depletion, may be associated with increased platelet count in HD patients,[6] which may predispose to thromboembolic events. Both "targeted" [42] and "achieved" [24] hemoglobin levels above $13 \mathrm{~g} / \mathrm{dL}$ are associated with increased mortality. Since many long-term HD patients with such excessively high hemoglobin levels have been administered high ESA doses, revisiting strategies to identify modifiable risk factors of ESA hyporesponsiveness is of high priority. ESA hyporesponsiveness may be a main contributor to hemoglobin variability,[8] which per se is associated with poor outcomes among CKD patients.[9,10] Evidence suggests that hemoglobin variability is common in CKD and that most patients spend a significant amount of time outside their target range.[45]

Using repeated measure models that extracted the individual patient response to ESA from the population response, which is usually due to "confounding by medical indication",[5,34] we examined a number of clinically relevant and modifiable correlates of ESA-

hyporesponsiveness (Table 2) including having a dialysis catheter, high body mass index, low dialysis dose $(\mathrm{Kt} / \mathrm{V})$, poor nutritional status (reflected by low serum albumins and TIBC levels and low protein intake), iron depletion, hyperparathyroidism, and high-turnover bone disease. The foregoing conditions are also believed to be the major contributors to hemoglobin variability.[8] Our foregoing longitudinal findings pertaining to the higher likelihood of ESA hyporesponsiveness in the presence of protein-energy wasting [46] are in line of several previous cross-sectional studies that linked malnutrition-inflammation complex to refractory anemia.[47-49]

We also found that markers of low iron stores, i.e., serum ferritin $<200 \mathrm{ng} / \mathrm{ml}$ and ISAT $<20 \%$ were strong predictors of ESA hyporesponsiveness, whereas ferritin level in the 500-1,200 ng/ $\mathrm{ml}$ range and ISAT above $30 \%$ were associated with greater ESA response. The KDOQI guidelines recommend ISAT $>20 \%$ and serum ferritin $>200 \mathrm{ng} / \mathrm{ml}$ in long-term HD patients. [50] Achieving an optimal iron status in CKD patients is an important endeavor, because hemoglobin synthesis is suboptimal without adequate background presence of iron.[51] HD patients may lose iron as a result of latent to overt gastro-intestinal or other bleeding tendencies, frequent blood testing and other blood losses.[52] It is estimated that almost half of all longterm HD patients in the USA have a serum ferritin $>500 \mathrm{ng} / \mathrm{ml}$.[25] Using a novel iron detection imaging tool, a recent study found that serum ferritin in CKD patients is correlated with liver iron stores.[53] Hence, even though there are other contributors of moderate hyperferritinemia including malnutrition-inflammation complex or liver disease,[54] increased iron stores remains a main determinant of moderately high serum ferritin level.[55] Indeed, even though debates about withholding IV iron administration in HD patients with ferritin level above 500 $\mathrm{ng} / \mathrm{ml}$ continues, $[18,19]$ a recent randomized controlled trial showed that in ESAhyporesponsive and anemic HD patients with feritin ranges between 500 and 1,200 ng/ml, administration of $1 \mathrm{gm}$ of iron gluconate, besides increasing the ESA dose, was safe and 
improved hemoglobin level.[56] Moreover, a recent study showed that serum ferritin levels between 200 and $1,200 \mathrm{ng} / \mathrm{ml}$ was not associated with increased death risk and that moderately high serum ISAT levels in 30\% to 50\% range was related to the greatest survival.[25] Besarab et al [57] found that HD patients whose ISAT was in the 30-50\% range for 6 months had a $40 \%$ reduction in administered ESA dose compared to patients whose ISAT remained in the $20-30 \%$ range.

We found that ESA-hyporesponsiveness was related to higher serum PTH and alkaline phosphatase values, whereas the greatest ESA responsiveness was associated with the mid to low PTH range (150-300 pg/mL) and low-normal alkaline phosphatase ( $<80 \mathrm{U} / \mathrm{L})$ (Figure 3). Both high levels of PTH and alkaline phosphatase are associated with increased death risk in long-term HD patients, $[21,23]$ indicating that the observed ESA-hyporesponse relationships may be epiphenomenon. Nevertheless, hyperparathyroidism may directly cause ESAhyporesponsiveness by diminishing endogenous erythropoietin synthesis, reducing bone marrow erythroid progenitors, and shortening erythrocyte survival.[58,59] Indirect effects include the association of renal osteodystrophy with bone marrow fibrosis,[15] confirmed by the observation of the restored bone marrow space and concomitant rise of serum erythropoietin concentrations after parathyroidectomy.[60] Rao et al [15] showed that HD patients with bone marrow fibrosis $\geq 1 \%$ required a mean ESA dose $90 \%$ higher than those with $<1 \%$ fibrosis, and patients with greater ESA-responsiveness had higher mean PTH levels than ESA-

hyporesponders, i.e, $266 \pm 322 \mathrm{pg} / \mathrm{mL}$ vs. $800 \pm 648 \mathrm{pg} / \mathrm{mL}$. Hence, ESA-hyporesponsiveness can potentially be corrected through therapy with active vitamin $\mathrm{D}$ and/or calcimimetics, which reduce PTH secretion and improve high turn-over bone disease as shown by a reduction in serum alkaline phosphatase.[58] Indeed, several uncontrolled studies have indicated that patients who respond to calcitriol or its analogs also show an increase in hemoglobin levels. [61]

Our study should be qualified for its observational-epidemiological nature, its retrospective nature, missing hospitalization data, and lack of explicit biomarkers of osteodystrophy and markers of inflammation, especially since inflammation appears associated for ESA hyporesponsiveness.[47] Furthermore, we have analyzed the association between the averaged ESA dose and quarterly hemoglobin values within the same calendar quarter without accounting for the short period of time required between the exposure (ESA) and outcome (hemoglobin). Nevertheless, given the 13-week length of each calendar quarter, the required time-lag of the said association is likely included within the studied calendar quarters. Another limitation of our analysis is that it is based on only 12-month period of the cohort, rather than a longitudinal follow-up of several years. Nonetheless, changes in practice pattern over longer periods of time may further confound the ESA-hemoglobin association. Any insight into the short-term ESA response of dialysis patients is of major clinical relevance. Moreover, the ESA dose during hospitalization was not accounted for, and statistical interactions or subgroup (stratified) analyses were not examined in this study. The comorbid conditions, which were extracted from the Form 2728 and which included 12\% missing values, may be outdated and underrepresent the current comorbidity of the prevalent HD patients. Finally, variation in serum alkaline phosphatase levels, presumably a biomarker of bone turnover activity, may be related non-bone related conditions such as liver disease, esp. since we used total alkaline phosphatase and not its bone-specific subtype.

The strengths of our study include: (1) contemporary nature, since all patient data were obtained from the $21^{\text {st }}$ century (2001-2002); (2) uniform laboratory measurements with all laboratory data obtained from one single facility, (3) large sample size; (4) 3-month averaged laboratory data, in that most values are the means of several measurements to minimize measurement variability; and (5) use of repeated measure models to calculate and rank ESA responsiveness coefficients that is separated from ESA-hemoglobin association at the population level. 
Moreover, by excluding HD patients who died within a short period of time, serum ferritin in our selected cohort may have lower correlation with inflammation and immediate death risk, especially since some, but not all, sicker patients were removed. Under these circumstances, serum ferritin may more appropriately serve as a measure of iron stores.

In conclusion, we showed that among surviving prevalent HD patients who had received ESA, such conditions as comorbid states, protein-energy wasting, hyperparathyroidism, high turnover bone disease and iron depletion are associated with ESA hyporesponsiveness. Given recent studies that showed increased death risk with targeting high hemoglobin levels using higher ESA doses,[41-43] and given a potential link between high ESA doses and increased platelet count in the setting of iron depletion,[6] it is prudent to seek strategies that circumvent the need for excessively high ESA doses. Optimizing the ESA responsiveness is not only an effective mean to that end but it may also provide a more cost-effective approach to CKD anemia management. $[62,63]$ Any intervention that can enhance the sensitivity of CKD patients to ESA therapy, may lead to lower ESA dosage and utilization white improving safety and reducing the costs. Even though substantial system-wide cost savings can be achieved in the management of anemia in HD patients through the more aggressive use of IV iron supplementation [64] and despite recent studies about short-term safety and benefit of IV iron, active vitamin $\mathrm{D}$ and calcimimetics, additional controlled trials are needed to verify the longterm impact of these medications on outcomes.

\section{Acknowledgments}

The abstracts of this paper were accepted for oral and poster presentation during the American Society of Nephrology (ASN) annual conferences, November 1-6, 2007, in San Francisco, CA, and November 6-9, 2008, in Philadelphia, PA.

Support: This study was supported by Dr Kalantar-Zadeh's research grants from the National Institute of Diabetes, Digestive and Kidney Disease of the National Institute of Health (R01 DK078106), American Heart Association grant (0655776Y), a research grant from DaVita Clinical Research (DCR), and a philanthropist grant from Mr. Harold Simmons. The analyses related to markers of high-turnover bone disease were additionally supported by an investigator initiated grant from Abbott. The DCR provided the clinical data for this research project.

Financial Disclosure

Dr. Kalantar-Zadeh has received grants and/or honoraria from Abbott (manufacturer of Zemplar ${ }^{\mathrm{TM}}$ ), AMAG (manufacturer of ferumoxytol), Amgen (manufacturer of Epogen ${ }^{\mathrm{TM}}$, Aranesp ${ }^{\mathrm{TM}}$ and Sensipar ${ }^{\mathrm{TM}}$ ), and Watson (manufacturer of Ferrlecit ${ }^{\mathrm{M}}$ ). Dr. Kovesdy has received grants and/or honoraria from Abbott, Amgen and AMAG.

\section{References}

1. Weiss G, Goodnough LT. Anemia of chronic disease. N Engl J Med 2005;352:1011-1023. [PubMed: 15758012]

2. Levin A. The treatment of anemia in chronic kidney disease: understandings in 2006. Curr Opin Nephrol Hypertens 2007;16:267-271. [PubMed: 17420672]

3. Brimble KS, Clase CM. Hemoglobin variability in dialysis patients. J Am Soc Nephrol 2007; 18:22182220. [PubMed: 17627931]

4. Berns JS, Fishbane S. Hemoglobin variability: random fluctuation, epiphenomenon, or phenomenon? Semin Dial 2006;19:257-259. [PubMed: 16689980]

5. Cotter D, Zhang Y, Thamer M, Kaufman J, Hernan MA. The effect of epoetin dose on hematocrit. Kidney Int 2008;73:347-353. [PubMed: 18004296]

6. Streja E, Kovesdy CP, Greenland S, Kopple JD, McAllister CJ, Nissenson AR, Kalantar-Zadeh K. Erythropoietin, iron depletion, and relative thrombocytosis: a possible explanation for hemoglobinsurvival paradox in hemodialysis. Am J Kidney Dis 2008;52:727-736. [PubMed: 18760517] 
7. Phrommintikul A, Haas SJ, Elsik M, Krum H. Mortality and target haemoglobin concentrations in anaemic patients with chronic kidney disease treated with erythropoietin: a meta-analysis. Lancet 2007;369:381-388. [PubMed: 17276778]

8. Kalantar-Zadeh, k; Aronoff, GR. Hemoglobin Variability in Anemia of Chronic Kidney Disease. J Am Soc Neph. 2008[in press]

9. Yang W, Israni RK, Brunelli SM, Joffe MM, Fishbane S, Feldman HI. Hemoglobin variability and mortality in ESRD. J Am Soc Nephrol 2007;18:3164-3170. [PubMed: 18003781]

10. Gilbertson DT, Ebben JP, Foley RN, Weinhandl ED, Bradbury BD, Collins AJ. Hemoglobin level variability: associations with mortality. Clin J Am Soc Nephrol 2008;3:133-138. [PubMed: 18045862]

11. Kilpatrick RD, Critchlow CW, Fishbane S, Besarab A, Stehman-Breen C, Krishnan M, Bradbury BD. Greater epoetin alfa responsiveness is associated with improved survival in hemodialysis patients. Clin J Am Soc Nephrol 2008;3:1077-1083. [PubMed: 18417744]

12. Berns JS, Elzein H, Lynn RI, Fishbane S, Meisels IS, Deoreo PB. Hemoglobin variability in epoetintreated hemodialysis patients. Kidney Int 2003;64:1514-1521. [PubMed: 12969173]

13. Gunnell J, Yeun JY, Depner TA, Kaysen GA. Acute-phase response predicts erythropoietin resistance in hemodialysis and peritoneal dialysis patients. Am J Kidney Dis 1999;33:63-72. [PubMed: 9915269]

14. Kalantar-Zadeh K, Hoffken B, Wunsch H, Fink H, Kleiner M, Luft FC. Diagnosis of iron deficiency anemia in renal failure patients during the post-erythropoietin era. Am J Kidney Dis 1995;26:292299. [PubMed: 7645533]

15. Rao DS, Shih MS, Mohini R. Effect of serum parathyroid hormone and bone marrow fibrosis on the response to erythropoietin in uremia. N Engl J Med 1993;328:171-175. [PubMed: 8417383]

16. Van Wyck DB, Bailie G, Aronoff G. Just the FAQs: frequently asked questions about iron and anemia in patients with chronic kidney disease. Am J Kidney Dis 2002;39:426-432. [PubMed: 11840388]

17. Horl WH. Clinical aspects of iron use in the anemia of kidney disease. J Am Soc Nephrol 2007;18:382393. [PubMed: 17229908]

18. KDOQI Clinical Practice Guideline and Clinical Practice Recommendations for anemia in chronic kidney disease: 2007 update of hemoglobin target. Am J Kidney Dis 2007;50:471-530. [PubMed: 17720528]

19. National Kidney Foundation I. KDOQI clinical practice guidelines and clinical practice recommendations for anemia in chronic kidney disease. Am J Kid Dis 2006;47(suppl S3):146-146.

20. National Kidney Foundation I. Kidney Disease-Dialysis Outcome Quality Initiative: K/DOQI Clinical Practice Guidelines for bone metabolism and disease in chronic kidney disease. Am J Kidney Dis 2003;42:S1-S202. [PubMed: 14520607]

21. Regidor DL, Kovesdy CP, Mehrotra R, Rambod M, Jing J, McAllister CJ, Van Wyck D, Kopple JD, Kalantar-Zadeh K. Serum Alkaline Phosphatase Predicts Mortality among Maintenance Hemodialysis Patients. J Am Soc Nephrol. 200810.1681/ASN.2008010014[e-published ahead of print]

22. Blayney MJ, Pisoni RL, Bragg-Gresham JL, Bommer J, Piera L, Saito A, Akiba T, Keen ML, Young EW, et al. High alkaline phosphatase levels in hemodialysis patients are associated with higher risk of hospitalization and death. Kidney Int 2008;74:655-663. [PubMed: 18547993]

23. Kalantar-Zadeh K, Kuwae N, Regidor DL, Kovesdy CP, Kilpatrick RD, Shinaberger CS, McAllister CJ, Budoff MJ, Salusky IB, et al. Survival predictability of time-varying indicators of bone disease in maintenance hemodialysis patients. Kidney Int 2006;70:771-780. [PubMed: 16820797]

24. Regidor DL, Kopple JD, Kovesdy CP, Kilpatrick RD, McAllister CJ, Aronovitz J, Greenland S, Kalantar-Zadeh K. Associations between changes in hemoglobin and administered erythropoiesisstimulating agent and survival in hemodialysis patients. J Am Soc Nephrol 2006;17:1181-1191. [PubMed: 16565261]

25. Kalantar-Zadeh K, Regidor DL, McAllister CJ, Michael B, Warnock DG. Time-Dependent Associations between Iron and Mortality in Hemodialysis Patients. J Am Soc Nephrol 2005; 16:30703080. [PubMed: 16033854]

26. Kalantar-Zadeh K, Kilpatrick RD, Kuwae N, McAllister CJ, Alcorn H Jr, Kopple JD, Greenland S. Revisiting mortality predictability of serum albumin in the dialysis population: time dependency, 
longitudinal changes and population-attributable fraction. Nephrol Dial Transplant 2005;20:18801888. [PubMed: 15956056]

27. Shinaberger CS, Kilpatrick RD, Regidor DL, McAllister CJ, Greenland S, Kopple JD, Kalantar-Zadeh K. Longitudinal associations between dietary protein intake and survival in hemodialysis patients. Am J Kid Dis 2006;48:37-49. [PubMed: 16797385]

28. Kilpatrick RD, McAllister CJ, Kovesdy CP, Derose SF, Kopple JD, Kalantar-Zadeh K. Association between Serum Lipids and Survival in Hemodialysis Patients and Impact of Race. J Am Soc Nephrol 2007;18:293-303. [PubMed: 17167113]

29. Kalantar-Zadeh K, Kilpatrick RD, McAllister CJ, Miller LG, Daar ES, Gjertson DW, Kopple JD, Greenland S. Hepatitis C virus and death risk in hemodialysis patients. J Am Soc Nephrol 2007;18:1584-1593. [PubMed: 17429053]

30. Kalantar-Zadeh K, Kopple JD, Regidor DL, Jing J, Shinaberger CS, Aronovitz J, McAllister CJ, Whellan D, Sharma K. A1C and survival in maintenance hemodialysis patients. Diabetes Care 2007;30:1049-1055. [PubMed: 17337501]

31. Kovesdy CP, Regidor DL, Mehrotra R, Jing J, McAllister CJ, Greenland S, Kopple JD, KalantarZadeh K. Serum and dialysate potassium concentrations and survival in hemodialysis patients. Clin J Am Soc Nephrol 2007;2:999-1007. [PubMed: 17702709]

32. Longenecker JC, Coresh J, Klag MJ, Levey AS, Martin AA, Fink NE, Powe NR. Validation of comorbid conditions on the end-stage renal disease medical evidence report: the CHOICE study. Choices for Healthy Outcomes in Caring for ESRD. J Am Soc Nephrol 2000;11:520-529. [PubMed: 10703676]

33. Eschbach JW, Kelly MR, Haley NR, Abels RI, Adamson JW. Treatment of the anemia of progressive renal failure with recombinant human erythropoietin. N Engl J Med 1989;321:158-163. [PubMed: 2747747]

34. Shinaberger CS, Kopple JD, Kovesdy CP, McAllister CJ, van Wyck D, Greenland S, Kalantar-Zadeh K. Ratio of Paricalcitol Dosage to Serum Parathyroid Hormone Level and Survival in Maintenance Hemodialysis Patients. Clin J Am Soc Nephrol. 200810.2215/CJN.01760408

35. Diggle, P.; Heagerty, P.; Liang, KY.; Zeger, SL. Analysis of longitudinal data. Oxford University Press; 2002.

36. Coyne DW. Use of epoetin in chronic renal failure. Jama 2007;297:1713-1716. [PubMed: 17440149]

37. Steinbrook R. Medicare and erythropoietin. N Engl J Med 2007;356:4-6. [PubMed: 17202449]

38. Thamer M, Zhang Y, Kaufman J, Cotter D, Dong F, Hernan MA. Dialysis facility ownership and epoetin dosing in patients receiving hemodialysis. Jama 2007;297:1667-1674. [PubMed: 17440144]

39. United States Renal Data System: United States Renal Data System. 2006 Annual Data Report Atlas of Chronic Kidney Disease \& End-Stage Renal Disease in the United States. Am J Kidney Dis 2007;49:1-296. [PubMed: 17185139]

40. Cotter DJ, Stefanik K, Zhang Y, Thamer M. Improved survival with higher hematocrits: where is the evidence? Semin Dial 2004;17:181-183. [PubMed: 15144538]

41. Besarab A, Bolton WK, Browne JK, Egrie JC, Nissenson AR, Okamoto DM, Schwab SJ, Goodkin DA. The effects of normal as compared with low hematocrit values in patients with cardiac disease who are receiving hemodialysis and epoetin. N Engl J Med 1998;339:584-590. [PubMed: 9718377]

42. Singh AK, Szczech L, Tang KL, Barnhart H, Sapp S, Wolfson M, Reddan D. Correction of anemia with epoetin alfa in chronic kidney disease. N Engl J Med 2006;355:2085-2098. [PubMed: 17108343]

43. Drueke TB, Locatelli F, Clyne N, Eckardt KU, Macdougall IC, Tsakiris D, Burger HU, Scherhag A. Normalization of hemoglobin level in patients with chronic kidney disease and anemia. N Engl J Med 2006;355:2071-2084. [PubMed: 17108342]

44. Zhang Y, Thamer M, Stefanik K, Kaufman J, Cotter DJ. Epoetin requirements predict mortality in hemodialysis patients. Am J Kidney Dis 2004;44:866-876. [PubMed: 15492953]

45. Ebben JP, Gilbertson DT, Foley RN, Collins AJ. Hemoglobin level variability: associations with comorbidity, intercurrent events, and hospitalizations. Clin J Am Soc Nephrol 2006;1:1205-1210. [PubMed: 17699349] 
46. Fouque D, Kalantar-Zadeh K, Kopple J, Cano N, Chauveau P, Cuppari L, Franch H, Guarnieri G, Ikizler TA, et al. A proposed nomenclature and diagnostic criteria for protein-energy wasting in acute and chronic kidney disease. Kidney Int 2008;73:391-398. [PubMed: 18094682]

47. Kalantar-Zadeh K, McAllister CJ, Lehn RS, Lee GH, Nissenson AR, Kopple JD. Effect of malnutrition-inflammation complex syndrome on EPO hyporesponsiveness in maintenance hemodialysis patients. Am J Kidney Dis 2003;42:761-773. [PubMed: 14520627]

48. Kalantar-Zadeh K, Block G, McAllister CJ, Humphreys MH, Kopple JD. Appetite and inflammation, nutrition, anemia and clinical outcome in hemodialysis patients. Am J Clin Nutr 2004;80:299-307. [PubMed: 15277149]

49. Stenvinkel P, Barany P. Anaemia, rHuEPO resistance, and cardiovascular disease in end-stage renal failure; links to inflammation and oxidative stress. Nephrol Dial Transplant 2002;17 (Suppl 5):3237. [PubMed: 12091605]

50. Fishbane S. Upper Limit of Serum Ferritin: Misinterpretation of the 2006 KDOQI Anemia Guidelines. Semin Dial. 2008

51. Fishbane S, Kalantar-Zadeh K, Nissenson AR. Serum ferritin in chronic kidney disease: reconsidering the upper limit for iron treatment. Semin Dial 2004;17:336-341. [PubMed: 15461737]

52. Kalantar-Zadeh K, Streja E, Miller JE, Nissenson AR. Intravenous Iron vs. Erythropoiesis Stimulating Agents: Friends or Foes in Treating CKD Anemia? Adv Chronic Kidney Dis. 2009[in press]

53. Canavese C, Bergamo D, Ciccone G, Longo F, Fop F, Thea A, Martina G, Piga A. Validation of serum ferritin values by magnetic susceptometry in predicting iron overload in dialysis patients. Kidney Int 2004;65:1091-1098. [PubMed: 14871430]

54. Smith RJ, Davis P, Thomson AB, Wadsworth LD, Fackre P. Serum ferritin levels in anemia of rheumatoid arthritis. J Rheumatol 1977;4:389-392. [PubMed: 604478]

55. Kalantar-Zadeh K, Kalantar-Zadeh K, Lee GH. The fascinating but deceptive ferritin: To measure it or not to measure it in chronic kidney disease? Clin J Am Soc Neph 2006;1(supplement):S9-S18.

56. Coyne DW, Kapoian T, Suki W, Singh AK, Moran JE, Dahl NV, Rizkala AR. Ferric gluconate is highly efficacious in anemic hemodialysis patients with high serum ferritin and low transferrin saturation: results of the Dialysis Patients' Response to IV Iron with Elevated Ferritin (DRIVE) Study. J Am Soc Nephrol 2007;18:975-984. [PubMed: 17267740]

57. Besarab A, Amin N, Ahsan M, Vogel SE, Zazuwa G, Frinak S, Zazra JJ, Anandan JV, Gupta A. Optimization of epoetin therapy with intravenous iron therapy in hemodialysis patients. J Am Soc Nephrol 2000;11:530-538. [PubMed: 10703677]

58. Brancaccio D, Cozzolino M, Gallieni M. Hyperparathyroidism and anemia in uremic subjects: a combined therapeutic approach. J Am Soc Nephrol 2004;15 (Suppl 1):S21-24. [PubMed: 14684666]

59. Papayannopoulou, T.; D’Andrea, AD.; Abkowitz, JL.; Migliaccio, AR. Biology of erythropoiesis, erythroid differentiation, and maturation. In: Hoffman, R.; Benz, EJ.; Shattil, SJ., editors. Hematology Basic Principles and Practice. Vol. 4. Philadelphia, PA: Elsevier Churchill Livingstone; 2005. p. 267-288.

60. Gallieni M, Corsi C, Brancaccio D. Hyperparathyroidism and anemia in renal failure. Am J Nephrol 2000;20:89-96. [PubMed: 10773607]

61. Goicoechea M, Vazquez MI, Ruiz MA, Gomez-Campdera F, Perez-Garcia R, Valderrabano F. Intravenous calcitriol improves anaemia and reduces the need for erythropoietin in haemodialysis patients. Nephron 1998;78:23-27. [PubMed: 9453399]

62. Courtney AE, McNamee PT, Maxwell AP. Cost should be the principal determinant of choice of erythropoiesis-stimulating agent in chronic haemodialysis patients. Nephron Clin Pract 2007;107:c14-19. [PubMed: 17664890]

63. Churchill DN, Macarios D, Attard C, Kallich J, Goeree R. Costs associated with erythropoiesisstimulating agent administration to hemodialysis patients. Nephron Clin Pract 2007;106:c193-198. [PubMed: 17596729]

64. Pizzi LT, Patel NM, Maio VM, Goldfarb DS, Michael B, Fuhr JP, Goldfarb NI. Economic implications of non-adherence to treatment recommendations for hemodialysis patients with anemia. Dialysis \& Transplantation 2006;35:660-671. 


\section{TECHNICAL APPENDIX \\ Detailed Statistical Methods}

To study the relation between blood hemoglobin and the prescribed ESA dose in HD patients, our biologically plausible assumption was that under normal conditions higher administered ESA dose should lead to higher hemoglobin levels. The simple linear regression model $\mathbf{Y}_{\mathbf{i}}=\boldsymbol{\beta} \mathbf{x}_{\mathbf{i}}+\mathbf{c}+\boldsymbol{\varepsilon}_{\mathbf{I}}$ can show this association in the following format:

$$
\text { Hemoglobin }_{\mathrm{i}}=\beta^{*} \mathrm{ESA}_{\mathrm{i}}+\mathrm{c}+\varepsilon_{\mathrm{i}}
$$

[EF6] The foregoing regression equation indicates that at any given point in time, the achieved hemoglobin level of the $i^{\text {th }}$ person $\left(\right.$ Hemoglobin $\left._{\mathbf{i}}\right)$ is a function of the averaged prescribed ESA dose in the same person $\left(\mathbf{E S A}_{\mathbf{i}}\right)$ with a response coefficient $(\boldsymbol{\beta})$, which is expected to be a positive number if higher rHuEPO dose indeed leads to higher hemoglobin levels, plus the intercept (c) and some residue due to other factors $\left(\boldsymbol{\varepsilon}_{\mathbf{i}}\right)$.

We hypothesized, however, that in reality, HD patients with ESA-hyporesponsiveness receive higher ESA doses, whereas those who are enhanced ESA-responsiveness with higher hemoglobin levels would receive lower doses. This so-called "confounding by medical indication" (CMI), leads to a negative response coefficient $(\boldsymbol{\beta})$ in cross-sectional regression models at the population level (Figure 1). As a result, within large HD patient populations, a higher ESA dose is paradoxically associated with a lower hemoglobin level. Nevertheless, within each individual, a higher ESA dose should still be expected to yield higher hemoglobin response over time. Hence, a cross-sectional linear regression model at population level yields counterintuitively negative associations between the prescribed ESA dose and the achieved hemoglobin level due to the CMI, whereas in longitudinal models at individual level the association should be different.

To separate the population (cross-sectional) effect, which is confounded by the CMI, from the individual (longitudinal) effect, which represents the true response, we employed mixed model (SAS proc mixed) with a random intercept and ESA as a random effect with an unstructured covariance matrix.[35] The repeated measure model is: $\mathbf{Y}_{\mathbf{i j}}=\boldsymbol{\beta}_{\mathbf{C}} \mathbf{x}_{\mathbf{i 1}}+\boldsymbol{\beta}_{\mathbf{L}}\left(\mathbf{x}_{\mathbf{i j}}-\mathbf{x}_{\mathbf{i 1}}\right)+\mathbf{c}_{\mathbf{i}}+$ $\varepsilon_{i j ~[E F 7]}$ where $x_{i j}$ is the prescribed dose of ESA for the $i^{\text {th }}$ MHD patients during the $j^{\text {th }}$ calendar quarter, and $\mathrm{Y}_{\mathrm{ij}}$ is the achieved hemoglobin level for the ith person during the jth calendar quarter when hemoglobin response is modeled over the 4 consecutive calendar quarters (seasons) between July 2001 and June 2002:[EF8]

$$
\text { Hemoglobin }_{\mathrm{ij}}=\beta_{\mathrm{C} *} \mathrm{ESA}_{\mathrm{i} 1}+\beta_{\mathrm{Li} *}\left(\mathrm{ESA}_{\mathrm{ij}}-\mathrm{ESA}_{\mathrm{i} 1}\right)+\mathrm{c}_{\mathrm{i}}+\varepsilon_{\mathrm{ij}}
$$

In the above model, $\boldsymbol{\beta}_{\mathbf{C}}$ represents the differences in average hemoglobin across the population, i.e., the cross-sectional response coefficient or the population $\beta$. It is a single $\beta$ for the entire HD patient population and a negative number due to the CMI. On the contrary, $\boldsymbol{\beta}_{\mathbf{L i}}$ represents the expected biologically plausible changes in hemoglobin over time i.e. over up to 4 calendar quarters, as a result of response to prescribed ESA dose, and, hence, is the longitudinal response coefficient or the individual $\beta$. Each HD patient has his or her unique $\boldsymbol{\beta}_{\mathbf{L}}$ value hence $\boldsymbol{\beta}_{\mathbf{L i}}$ ). In the above-mentioned mixed model, " $\mathrm{i}$ " is a number between 1 and $\mathrm{n}$ (the total number of HD patients in the cohort); hence, we can rank patients according to the magnitude of their individual $\boldsymbol{\beta}_{\mathbf{L}}$ values and rank them accordingly to create 4 incremental quartiles, i.e., from the lowest responsive (ESA-hyporesponsive) to the highest responsive patients. In this type of hierarchical modeling of the individual's response to ESA, the "individual" is considered the 
second tier unit, while measurements of hemoglobin over time within each individual are considered the first tier unit. The model was specified with a random slope and intercept, allowing each individual to vary both in their baseline hemoglobin levels, that is, when no ESA is administered, and their response to ESA over time.

We then employed logistic regression modeling, in that the response variable was created as a dichotomous variable and defined as "most responsive" or 1 if the individual ESA response coefficient $\left(\boldsymbol{\beta}_{\mathbf{L}}\right)$ was in the highest (75\%-100\%) of the beta values, and defined as "least responsive" or 0 if $\boldsymbol{\beta}_{\mathbf{L}}$ was in the $0 \%$ to $25 \%$ range. For each analysis both the unadjusted and case-mix multivariate adjusted models were examined as described in the text of the manuscript. 


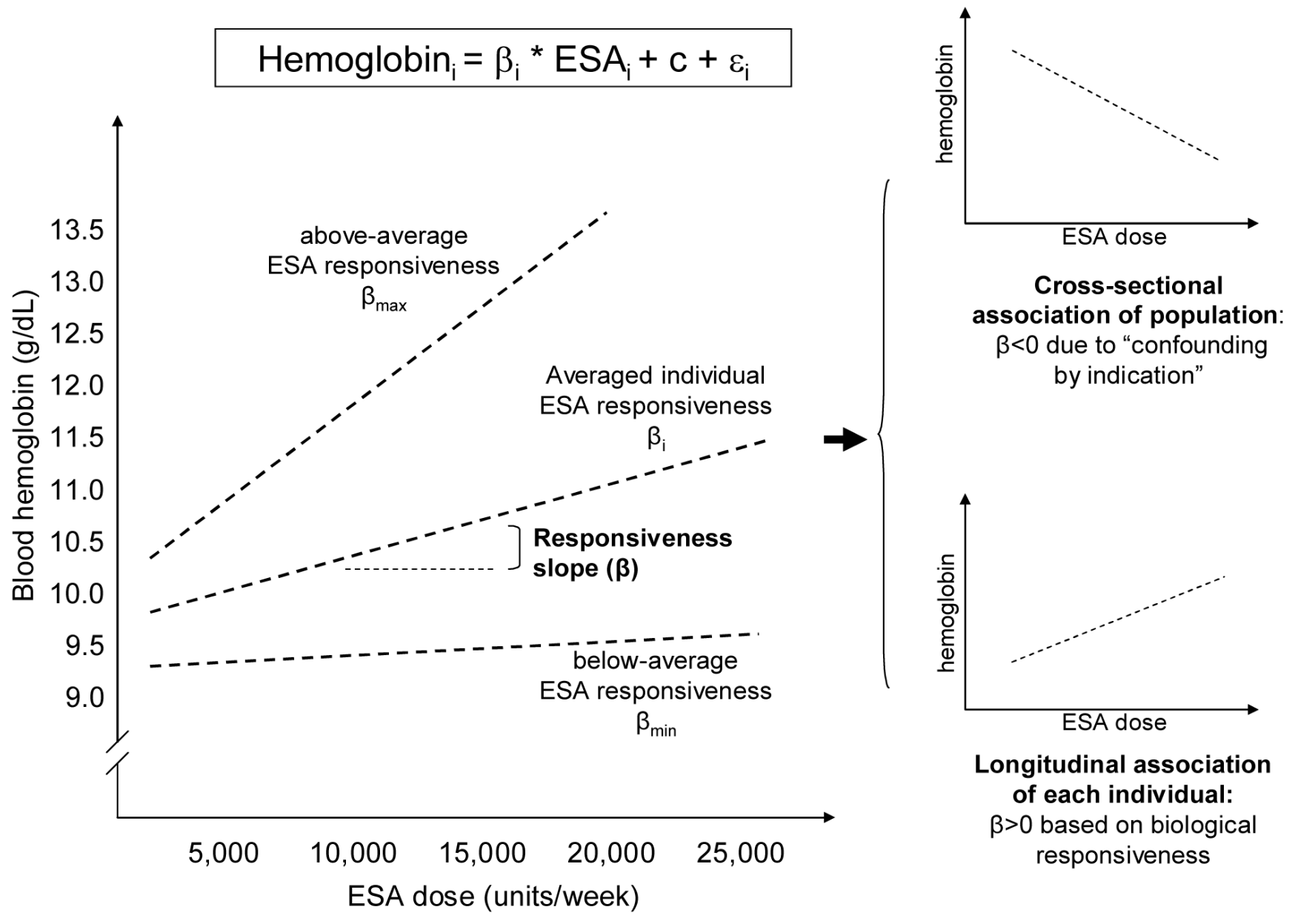

Figure 1.

[EF5] Schematic representation of erythropoietin stimulating agent (ESA) responsiveness. Whereas the biological response of hemoglobin to ESA at individual HD patient level is positive longitudinally (responsiveness slope or $\beta>0$ ), at the population level in cross-sectional analyses the ESA responsiveness appears negative $(\beta<0)$ due to the "confounding by medical indication", i.e., individuals with higher hemoglobin levels tend to receive lower ESA dose, whereas those with lower ESA dose and worse ESA responsiveness receive higher ESA dose (see Technical Appendix for details). 

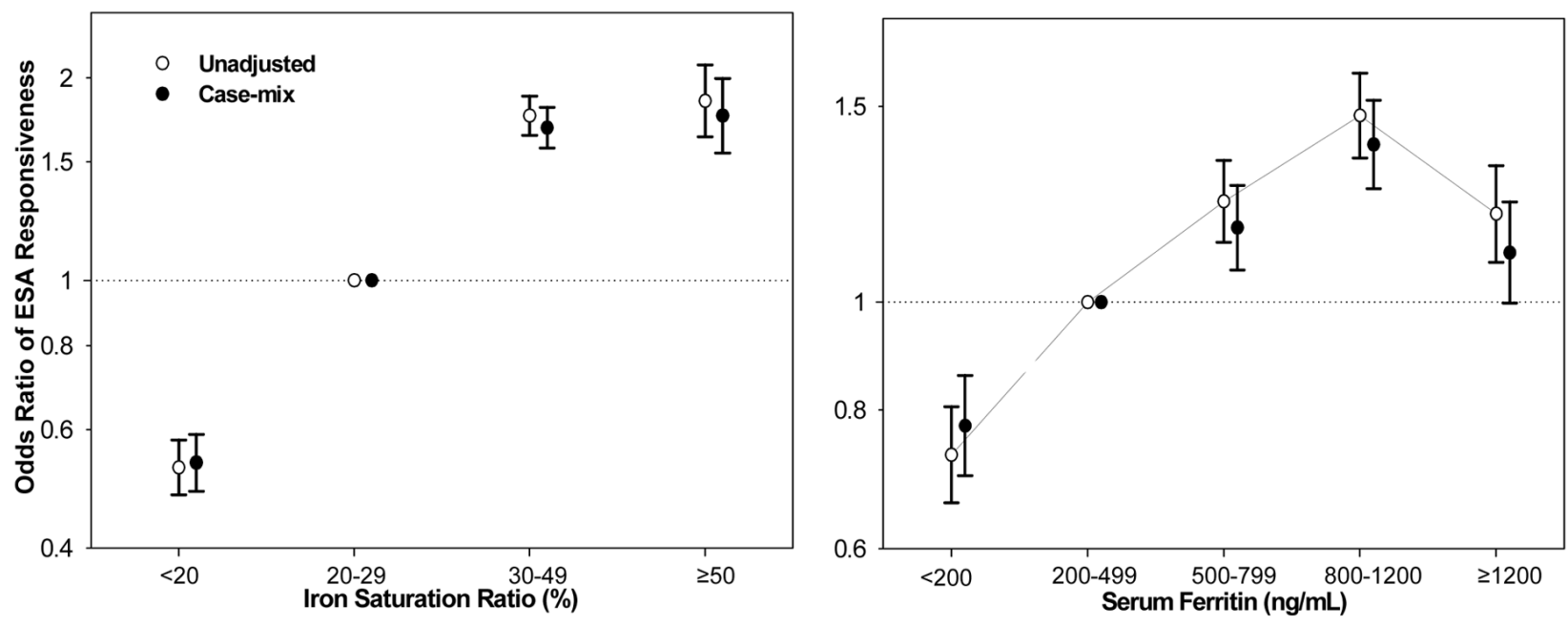

Figure 2.

Odds ratio (OR) of erythropoietin stimulating agent (ESA)-responsiveness for iron markers before and after adjustment for case-mix variables in 38,393 long-term hemodialysis patients. Left panel: OR of ESA responsiveness for selected ranges of serum iron saturated ratio (ISAT). Right panel: OR of ESA responsiveness for selected ranges of serum ferritin.

Footnote: Case-mix adjusted models are controlled for age, sex, race and ethnicity, diabetes mellitus and 11 pre-existing comorbid states, history of tobacco smoking, dialysis vintage, primary insurance, marital status, standardized mortality ratio, dialysis dose, dialysis catheter, and residual renal function. 

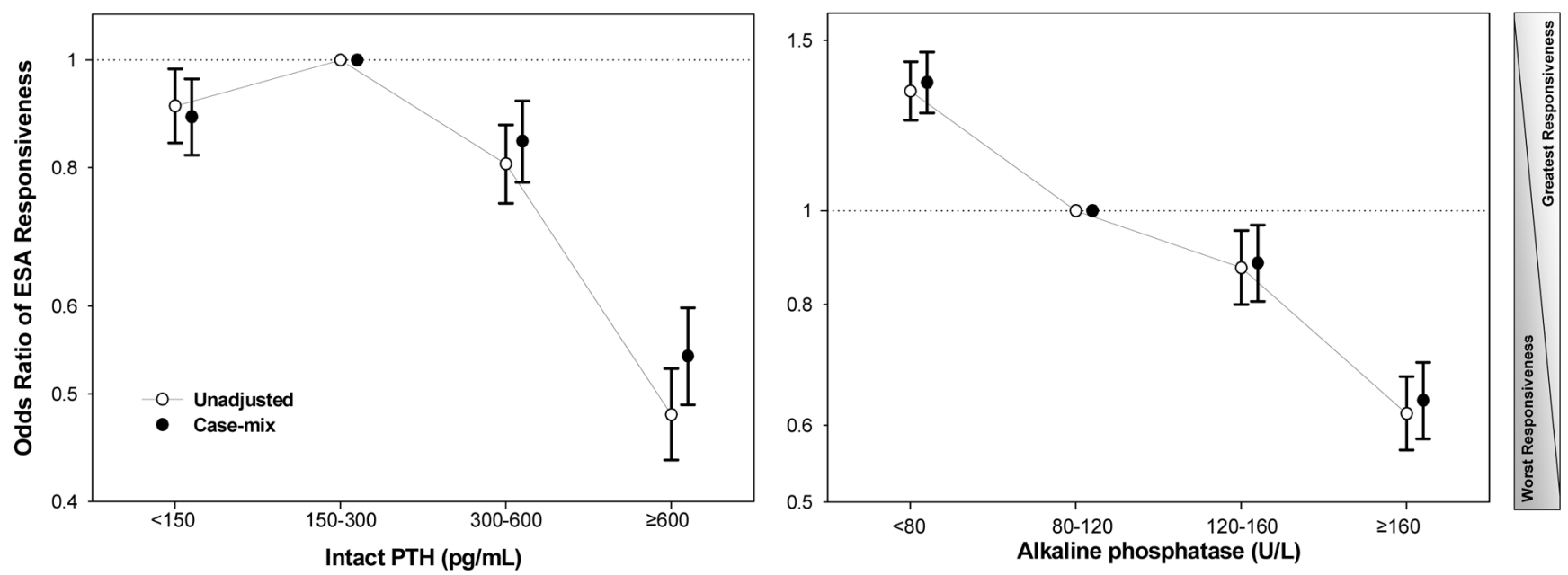

Figure 3.

Odds ratio (OR) of erythropoietin stimulating agent (ESA)-responsiveness for biomarkers of renal osteodystrophy before and after adjustment for case-mix variables in 38,393 long-term hemodialysis patients. Left panel: OR of ESA responsiveness for selected ranges of serum intact parathyroid hormone. Right panel: OR of ESA responsiveness for selected ranges of serum alkaline phosphatase.

Footnote: Case-mix adjusted models are controlled for age, sex, race and ethnicity, diabetes mellitus and 11 pre-existing comorbid states, history of tobacco smoking, dialysis vintage, primary insurance, marital status, standardized mortality ratio, dialysis dose, dialysis catheter, and residual renal function. 
Table 1

Demographic, clinical and laboratory data from the baseline calendar quarter in 38,393 long-term HD patients who received any dose of ESA for at least 3 out of 4 consecutive calendar quarters during the 7/2001-6/2002 period. ${ }^{* * *}$

\begin{tabular}{|c|c|c|c|c|}
\hline \multirow[t]{2}{*}{ Variable } & \multicolumn{4}{|c|}{ Quartile of the individual ESA-responsiveness coefficient $\left(\beta_{L}\right)$} \\
\hline & $\begin{array}{c}E S A- \\
\text { hyporesponsive 1st } \\
\text { quartile } \mathrm{N}=9,581\end{array}$ & 2nd quartile $N=9,579$ & $3^{\text {rd }}$ quartile $N=9,578$ & $\begin{array}{c}\text { most ESA - } \\
\text { responsive } \\
4^{\text {th }} \text { quartile } \\
\mathrm{N}=9,590\end{array}$ \\
\hline $\begin{array}{l}\text { Individual slope }\left(\beta_{\mathrm{L}}\right) \pm \mathrm{SD} \text { (the } \\
\text { range is in the parentheses) }\end{array}$ & $\begin{array}{c}0.301 \pm 0.033 \\
(0.001,0.336)\end{array}$ & $\begin{array}{c}0.344 \pm 0.004(0.336 \\
0.351)\end{array}$ & $\begin{array}{c}0.357 \pm 0.004(0.351 \\
0.366)\end{array}$ & $\begin{array}{c}0.389 \pm 0.026 \\
(0.366,0.652)\end{array}$ \\
\hline Age (years) & $59.0 \pm 15.0$ & $61.0 \pm 15.4$ & $61.5 \pm 15.3$ & $61.4 \pm 15.6$ \\
\hline Sex (\% women) & 48 & 46 & 46 & 46 \\
\hline Diabetes mellitus (\%) & 43 & 46 & 46 & 45 \\
\hline \multicolumn{5}{|l|}{ Race/ethnicity (\%): } \\
\hline Non-Hispanic Whites & 34 & 34 & 34 & 37 \\
\hline African Americans & 41 & 34 & 33 & 31 \\
\hline Hispanics & 12 & 16 & 17 & 15 \\
\hline $\begin{array}{l}\text { Dialysis vintage } 3-6 \text { month } \\
(\%)\end{array}$ & 18 & 21 & 17 & 13 \\
\hline $\begin{array}{l}\text { Primary insurance Medicare } \\
(\%)\end{array}$ & 66 & 66 & 68 & 70 \\
\hline Dialysis catheter access (\%) & 25 & 20 & 18 & 20 \\
\hline \multicolumn{5}{|l|}{ Pre-existing comorbidities $(\%)^{\dagger}$} \\
\hline $\operatorname{AIDS}^{c}$ & 1.3 & 1.1 & 1.2 & 1.2 \\
\hline HIV & 2.1 & 1.5 & 1.5 & 1.5 \\
\hline Cancer & 4.1 & 3.3 & 3.2 & 3.4 \\
\hline Congestive heart failure ${ }^{b}$ & 27 & 27 & 26 & 25 \\
\hline Ischemic heart disease ${ }^{c}$ & 17 & 18 & 17 & 18 \\
\hline Inability to ambulate & 2.7 & 2.1 & 2.0 & 2.0 \\
\hline Smoker $(\%)$ & 5.3 & 4.3 & 4.3 & 5.0 \\
\hline Body mass index $\left(\mathrm{kg} / \mathrm{m}^{2}\right)$ & $26.6 \pm 6.8$ & $26.0 \pm 6.0$ & $25.8 \pm 5.8$ & $25.8 \pm 5.6$ \\
\hline Residual renal function (Kru) & $0.13 \pm 0.75$ & $0.21 \pm 1.07$ & $0.24 \pm 0.96$ & $0.23 \pm 0.95$ \\
\hline $\mathrm{Kt} / \mathrm{V}$ (single pool) ${ }^{b}$ & $1.48 \pm 0.30$ & $1.54 \pm 0.31$ & $1.58 \pm 0.29$ & $1.58 \pm 0.31$ \\
\hline nPCR or nPNA (g/kg/day) & $0.98 \pm 0.25$ & $1.00 \pm 0.25$ & $1.02 \pm 0.24$ & $1.00 \pm 0.24$ \\
\hline Serum albumin $(\mathrm{g} / \mathrm{dL})$ & $3.67 \pm 0.42$ & $3.80 \pm 0.37$ & $3.85 \pm 0.34$ & $3.86 \pm 0.34$ \\
\hline creatinine ${ }^{c}(\mathrm{mg} / \mathrm{dL})$ & $9.6 \pm 3.3$ & $9.5 \pm 3.3$ & $9.6 \pm 3.2$ & $9.6 \pm 3.3$ \\
\hline TIBC (mg/dL) & $192 \pm 47$ & $199 \pm 42$ & $202 \pm 40$ & $205 \pm 40$ \\
\hline Iron (ng/ml) & $55 \pm 26$ & $60 \pm 25$ & $65 \pm 26$ & $67 \pm 26$ \\
\hline ISAT (\%) & $28 \pm 12$ & $30 \pm 11$ & $32 \pm 11$ & $33 \pm 12$ \\
\hline ferritin $(\mathrm{ng} / \mathrm{mL})$ & $570(321)$ & $583(314)$ & $637(302)$ & $663(306)$ \\
\hline phosphorus (mg/dL) & $5.9 \pm 1.7$ & $5.8 \pm 1.6$ & $5.7 \pm 1.5$ & $5.6 \pm 1.5$ \\
\hline calcium (mg/dL) & $9.2 \pm 0.8$ & $9.3 \pm 0.7$ & $9.3 \pm 0.7$ & $9.3 \pm 0.7$ \\
\hline intact PTH (pg/mL) & $260(185)$ & $230(149)$ & 227 (136) & $218(127)$ \\
\hline alkaline phosphatase (U/L) & $100 \pm 33$ & $94 \pm 27$ & $92 \pm 25$ & $91 \pm 26$ \\
\hline Blood hemoglobin (g/dL) & $11.4 \pm 1.3$ & $12.1 \pm 1.2$ & $12.2 \pm 1.0$ & $12.0 \pm 1.1$ \\
\hline
\end{tabular}




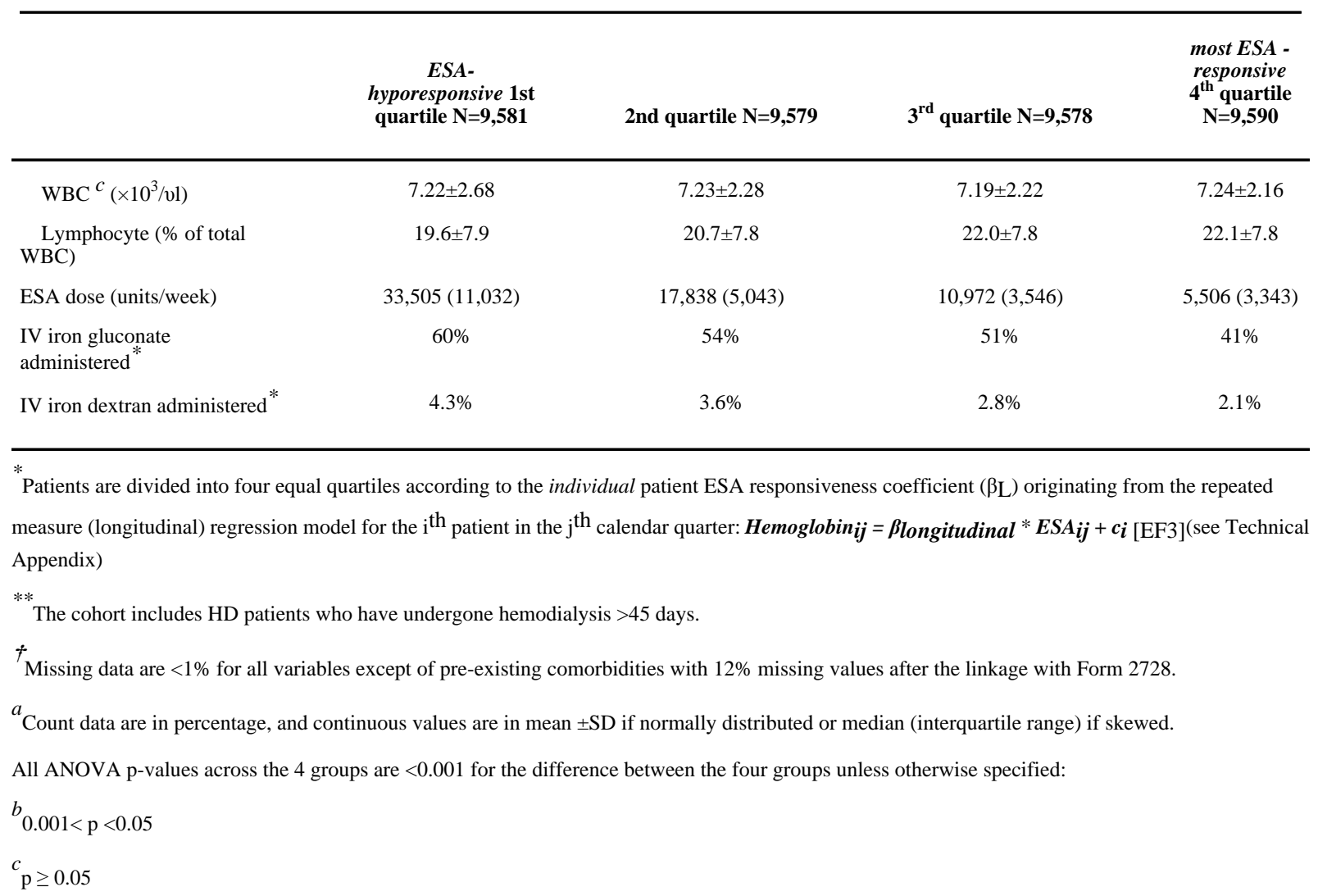

Abbreviations: ISAT: iron saturation ratio, TIBC: Total iron binding capacity, nPCR: normalized protein catabolic rate, nPNA: normalized protein nitrogen appearance, WBC: White blood cell count, ESA: erythropoiesis stimulating agent, PTH: parathyroid hormone

Note: Conversion factors for units: Albumin in $\mathrm{g} / \mathrm{dL}$ to $\mathrm{g} / \mathrm{L}, \times 10$; creatinine in $\mathrm{mg} / \mathrm{dL}$ to $\mu \mathrm{mol} / \mathrm{L}, \times 88.4$; ferritin in $\mathrm{ng} / \mathrm{mL}$ to $\mu \mathrm{g} / \mathrm{L}, \times 1 ;$ phosphorus in $\mathrm{mg} /$ $\mathrm{dL}$ to $\mathrm{mmol} / \mathrm{L}, \times 0.3229$; calcium in $\mathrm{mg} / \mathrm{dL}$ to $\mathrm{mmol} / \mathrm{L}, \times 0.2495$; parathyroid hormone in $\mathrm{pg} / \mathrm{mL}$ to $\mathrm{ng} / \mathrm{L}, \times 1$; hemoglobin in $\mathrm{g} / \mathrm{dL}$ to $\mathrm{g} / \mathrm{L}, \times 10$; white blood cell count in $10^{3} / \mu \mathrm{L}$ to $10^{9} / \mathrm{L}, \times 1$. 


\section{Table 2}

Odds of ESA-responsiveness for anemia management in 38,393 long-term HD patients, represented by the odds ratio (OR) [and 95\% confidence interval (CI)] of the highest vs. lowest quartile of ESA-responsiveness coefficient as shown in Table 1.

\begin{tabular}{|c|c|c|}
\hline Variable & Unadjusted OR $(95 \% \mathrm{CI})$ & Case-Mix adjusted OR (95\% CI) \\
\hline Age (each 10 year increase) & $1.11(1.09-1.13)$ & $1.06(1.06-1.11)$ \\
\hline Women (vs. men) & $0.90(0.85-0.95)$ & $0.78(0.73-0.83)$ \\
\hline Diabetics (vs. non-diabetics) & $1.08(1.02-1.14)$ & $1.04(0.98-1.11)$ \\
\hline African Americans (vs. non-Hispanic Whites) & $0.73(0.68-0.78)$ & $0.87(0.81-0.94)$ \\
\hline Hispanics (vs. non-Hispanic Whites) & $1.25(1.14-1.37)$ & $1.30(1.17-1.43)$ \\
\hline Dialysis vintage > 5 yrs (vs. $3-6$ mo) & $1.48(1.34-1.64)$ & $1.44(1.29-1.60)$ \\
\hline Primary insurance: Medicaid (vs. Medicare) & $0.70(0.62-0.80)$ & $0.76(0.66-0.87)$ \\
\hline Dialysis catheter (vs. arteriovenous graft or fistula) & $0.68(0.63-0.73)$ & $0.81(0.75-0.88)$ \\
\hline \multicolumn{3}{|l|}{ Pre-existing comorbid states: } \\
\hline AIDS & $0.91(0.67-1.22)$ & $1.80(1.07-3.03)$ \\
\hline HIV & $0.64(0.50-0.84)$ & $0.51(0.32-0.80)$ \\
\hline Cancer & $0.77(0.65-0.91)$ & $0.70(0.59-0.83)$ \\
\hline Congestive heart failure & $0.90(0.84-0.97)$ & $0.87(0.81-0.94)$ \\
\hline Dysrhythmia & $0.93(0.78-1.10)$ & $0.91(0.76-1.09)$ \\
\hline Ischemic heart disease & $1.06(0.98-1.15)$ & $0.98(0.89-1.08)$ \\
\hline Unable to ambulate & $0.69(0.56-0.85)$ & $0.77(0.62-0.96)$ \\
\hline Smoker status (vs. never smoked) & $0.92(0.80-1.06)$ & $1.01(0.87-1.17)$ \\
\hline Body mass index (each kg/m2 increase) & $0.98(0.97-0.98)$ & $0.99(0.98-0.99)$ \\
\hline Residual renal function (each Kru unit increase) & $1.14(1.10-1.19)$ & $1.04(1.01-1.07)$ \\
\hline $\mathrm{Kt} / \mathrm{V}$ single pool (each 0.1 unit increase) & $1.12(1.11-1.13)$ & $1.11(1.10-1.12)$ \\
\hline nPCR or nPNA (each g/kg/day increase) & $1.58(1.40-1.78)$ & $1.25(1.10-1.42)$ \\
\hline Serum albumin (each $0.2 \mathrm{~g} / \mathrm{dL}$ increase) ${ }^{*}$ & $1.31(1.29-1.33)$ & $1.31(1.29-1.34)$ \\
\hline creatinine (each $1 \mathrm{mg} / \mathrm{dL}$ increase) ${ }^{*}$ & $1.01(1.00-1.02)$ & $1.06(1.05-1.07)$ \\
\hline TIBC (each $10 \mathrm{mg} / \mathrm{dL}$ increase) $*$ & $1.07(1.06-1.07)$ & $1.07(1.06-1.08)$ \\
\hline iron (each $10 \mathrm{ng} / \mathrm{ml}$ increase) ${ }^{*}$ & $1.22(1.21-1.24)$ & $1.20(1.19-1.22)$ \\
\hline ISAT (each $10 \%$ increase) ${ }^{*}$ & $1.39(1.36-1.43)$ & $1.36(1.32-1.40)$ \\
\hline ferritin (each $100 \mathrm{ng} / \mathrm{mL}$ increase) ${ }^{*}$ & $1.02(1.02-1.03)$ & $1.02(1.01-1.02)$ \\
\hline phosphorus (each mg/dL increase) $*$ & $0.89(0.87-0.90)$ & $0.92(0.90-0.94)$ \\
\hline calcium (each $\mathrm{mg} / \mathrm{dL}$ increase) $*$ & $1.25(1.21-1.30)$ & $1.27(1.22-1.32)$ \\
\hline intact PTH (each $100 \mathrm{pg} / \mathrm{mL}$ increase) $*$ & $0.94(0.93-0.95)$ & $0.95(0.94-0.96)$ \\
\hline alkaline phosphatase (each $10 \mathrm{U} / \mathrm{L}$ increase) ${ }^{*}$ & $0.97(0.96-0.98)$ & $0.97(0.95-0.98)$ \\
\hline Blood WBC (each $10^{3} / \mu$ increase) $*$ & $1.00(0.99-1.01)$ & $0.99(0.98-1.01)$ \\
\hline lymphocytes (each \% increase) ${ }^{*}$ & $1.04(1.04-1.05)$ & $1.05(1.05-1.06)$ \\
\hline IV iron had to be administered $*$ & $0.84(0.83-0.86)$ & $0.86(0.85-0.88)$ \\
\hline
\end{tabular}

OR values in bold are statistically significant. OR $<1.0$ suggests worse ESA-hyporesponsiveness, whereas OR $>1$ indicates greater responsiveness to ESA treatment. ESA responsiveness was extracted based on the repeated measure model: $\boldsymbol{H e m o g l o b i n} \boldsymbol{i j}=\boldsymbol{\beta}$ longitudinal $* \boldsymbol{E S A} \boldsymbol{i j}+\boldsymbol{c} \boldsymbol{i}[$ EF4] $($ see Appendix). 
* All case-mix adjusted models include age, sex, race and ethnicity, diabetes mellitus and 11 pre-existing comorbid states, history of tobacco smoking, dialysis vintage, primary insurance, marital status, standardized mortality ratio, dialysis dose, dialysis catheter, and residual renal function. Each case-mix model that examines a laboratory variable or IV iron as the predictor includes only this variable as the predictor while adjusting for the above-mentioned covariates.

Abbreviations: ISAT: iron saturation ratio, TIBC: Total iron binding capacity, nPCR: normalized protein catabolic rate, nPNA: normalized protein nitrogen appearance, WBC: White blood cell count, ESA: erythropoiesis stimulating agent, PTH: parathyroid hormone 